\title{
ARTICLE \\ DIDS (4,4'-Diisothiocyanatostilbene-2,2'-disulfonate) directly inhibits caspase activity in HeLa cell lysates
}

\author{
E Benítez-Rangel ${ }^{1,2}$, MC López-Méndez ${ }^{1}$, L García ${ }^{1}$ and A Guerrero-Hernández ${ }^{1}$
}

Apoptosis is an important mechanism of cell demise in multicellular organisms and $\mathrm{Cl}^{-}$transport has an important role in the progression of the apoptotic volume decrease (AVD). DIDS (4,4'-Diisothiocyanatostilbene-2,2'-disulfonate) is one of the most commonly used $\mathrm{Cl}^{-}$transport inhibitors that eliminates or reduces different apoptotic hallmarks such as AVD, caspase-3 activity and DNA fragmentation. DIDS is also a protein crosslinker that alkylates either amino or thiol groups. Since caspases are thiol proteases, our aim was to study whether DIDS could directly inhibit the activity of these proteases. Here, we show that caspase activity induced by $4 \mathrm{~h}$ incubation with staurosporine was inhibited by DIDS in HeLa cells that were maintained in the absence of serum for $24 \mathrm{~h}$. Interestingly, the caspase-inhibitory effect of DIDS is downstream to the inhibition of cytochrome c release, suggesting that DIDS might be also acting at the apoptosome. Moreover, DIDS was able to inhibit capase-3, -9 , and -8 activities in cell lysates, implying that DIDS can react with and directly block caspases. Our data suggest that antiapoptotic activity of DIDS involves not only inhibition of the voltage-dependent anion channel (VDAC) at the mitochondria and $\mathrm{Cl}^{-}$channels at the plasma membrane, but also a third mechanism based on the direct inhibition of caspases.

Cell Death Discovery (2015) 1, 15037; doi:10.1038/cddiscovery.2015.37; published online 28 September 2015

\section{INTRODUCTION}

Apoptosis, one form of programmed cell death, is an important mechanism of cell demise in multicellular organisms. It has been established that ion fluxes, particularly $\mathrm{K}^{+}$efflux, are required for the apoptotic process. The early phase of apoptotic cell shrinkage is characterized by alterations in the activity and regulation of membrane ion channels. ${ }^{1-4} \mathrm{Cl}^{-}$transport activation is also required during apoptosis, ${ }^{3}$ mainly in the progression of the apoptotic volume decrease (AVD). ${ }^{5}$ It has been suggested that $\mathrm{Cl}^{-}$ channels and/or $\mathrm{Cl}^{-}$exchangers, such as $\mathrm{Cl}^{-} / \mathrm{HCO}_{3}^{-}$, have an apoptotic role in different cell types including HeLa cells, ${ }^{6}$ cerebellar granule neurons, ${ }^{7}$ salmonid cells, ${ }^{8}$ cardiomiocytes, ${ }^{9,10}$ renal proximal tubule cells, ${ }^{11}$ thymocytes ${ }^{12}$ and HL60 cells. ${ }^{13}$ This activation of $\mathrm{Cl}^{-}$transport occurs in response to different apoptosis inducers such as staurosporine (STS), tumor necrosis factor (TNF), cycloheximide, ${ }^{5,14}$ etoposide, $\mathrm{H}_{2} \mathrm{O}_{2}$ or Fas. ${ }^{14}$ One widely used substance to assess the participation of $\mathrm{Cl}^{-}$transport in apoptosis is DIDS (4,4'-Diisothiocyanatostilbene-2,2'-disulfonate), which is able to inhibit AVD triggered by different apoptotic inducers, ${ }^{5}$ and dramatically diminishes the number of apoptotic cells. ${ }^{7,9,11}$ DIDS has also been shown to block other hallmarks of apoptosis such as caspase-3 activity ${ }^{7,9,11,14}$ and DNA fragmentation. ${ }^{9}$

It has been demonstrated that inhibition of the $\mathrm{Cl}^{-} / \mathrm{HCO}_{3}^{-}$ exchanger by DIDS depends on two main characteristics of this molecule; namely, being an anion due to the presence of sulfonate and being an alkylating agent of amino groups due to the presence of isothiocyanate residues. Accordingly, the lysines alkylated by DIDS in the $\mathrm{Cl}^{-} / \mathrm{HCO}_{3}^{-}$exchanger have been identified. ${ }^{15}$ DIDS inhibits apoptosis by targeting anion transporters at two different cell locations, the plasma membrane and the outer mitochondrial membrane. The former reflects $\mathrm{Cl}^{-}$channels and
$\mathrm{Cl}^{-} / \mathrm{HCO}_{3}^{-}$exchangers that are sensitive to DIDS and are involved in $\mathrm{AVD}^{5}$ while the latter encompasses VDAC that participates in apoptosis as one of the pathways for releasing cytochrome $\mathrm{c}$ to the cytoplasm. ${ }^{16}$ The ability of DIDS to inhibit VDAC in intact cells ${ }^{17-19}$ implies that this inhibitor is able to reach the cell interior when it should not; because of its hydrophilic nature due to the presence of sulfonate groups. It is well known that DIDS is able to alkylate amino groups of lysine residues, ${ }^{20}$ but DIDS can also alkylate thiol residues in proteins. Indeed, it has been demonstrated that DIDS inhibits the activity of the plasma membrane $\mathrm{Ca}^{2+}$ ATPase (PMCA) by alkylating thiol groups of this protein. ${ }^{21}$ Moreover, DIDS induces the mitochondrial permeability transition pore by its thiol crosslinking activity. ${ }^{22,23}$ Since caspases are thiol proteases, we studied whether DIDS had any inhibitory effect on these proteases. We describe here a third mechanism for DIDS to inhibit apoptosis, which involves the direct inhibition of caspase activity. All these different targets of DIDS might explain its generalized antiapoptotic activity seen in different cell types. Importantly, our data show that $50 \mu \mathrm{M}$ DIDS is enough to inhibit apoptosis and that a higher concentration of DIDS $(500 \mu \mathrm{M})$ induced a new DEVDase activity (unrelated to caspase-3) that may explain the deleterious cellular effect that can also be displayed by DIDS.

\section{RESULTS}

DIDS that has been irreversibly bound to HeLa cells reduced both $\left[\mathrm{Ca}^{2+}\right]_{\mathrm{i}}$ and plasma membrane potential responses to histamine

To determine whether DIDS affected HeLa cells $\left[\mathrm{Ca}^{2+}\right]_{i}$ responses, we assessed both $\left[\mathrm{Ca}^{2+}\right]_{i}$ and plasma membrane potential in response to activation of $\mathrm{H} 1$ receptors by histamine. To this end, HeLa cells were preincubated with either 50 or $500 \mu \mathrm{M}$ DIDS for

\footnotetext{
${ }^{1}$ Department of Biochemistry CINVESTAV-IPN, Apdo. Postal 14-750, Mexico, D.F. México.

Correspondence: A Guerrero-Hernández (aguerrero@cinvestav.mx)

${ }^{2}$ Current address: Morphology and Function Unit, FES Iztacala, UNAM, Avenida de los Barrios No. 1, Los Reyes Iztacala, Tlalnepantla, México.

Received 18 July 2015; revised 13 August 2015; accepted 19 August 2015; Edited by N Barlev
} 
$2 \mathrm{~h}$ and washed to remove unbound DIDS. Preincubation with DIDS inhibited histamine-induced hyperpolarization of the PMP from $-9.2 \pm 1.6 \% \Delta \mathrm{F} / \mathrm{Fo}(n=3)$ in the absence of DIDS to $-4.8 \pm 0.79 \% \Delta \mathrm{F} / \mathrm{Fo}(n=3)$ and $-2.4 \pm 0.7 \% \Delta \mathrm{F} / \mathrm{Fo}(n=3)$ for 50 and $500 \mu \mathrm{M}$ DIDS, respectively (Figures $1 \mathrm{a}$ and $\mathrm{c}$ ). It is known that the histamine-induced hyperpolarization involves the activation of $\mathrm{Ca}^{2+}$-dependent $\mathrm{K}^{+}$channels, by $\mathrm{IP}_{3}$-mediated $\mathrm{Ca}^{2+}$ release from internal stores. ${ }^{24}$ Histamine-induced $\left[\mathrm{Ca}^{2+}\right]_{\mathrm{i}}$ responses were reduced from $192.5 \pm 47.8 \mathrm{nM}(n=3)$ in the absence of DIDS to $118.4 \pm 13.1 \mathrm{nM}(n=3)$ and $95.7 \pm 9.1 \mathrm{nM}(n=3)$ when cells were preincubated with 50 and $500 \mu \mathrm{M}$ DIDS, respectively (Figures $1 \mathrm{~b}$ and d). DIDS did not have any direct effect on Bisoxonol fluorescence (Supplementary Figure S1); however, this was not the case for Fura-2 fluorescence which was quenched by DIDS addition to cells loaded with Fura-2 (Supplementary Figure S2). For this reason cells were preincubated with DIDS and thoroughly washed to eliminate unbound DIDS before loading these cells with Fura-2 (Supplementary Figure S1). Therefore, this inhibitory effect of DIDS on histamine-induced $\left[\mathrm{Ca}^{2+}\right]_{i}$ response in washed cells, that was recorded in the absence of DIDS, suggests the irreversible alkylation of signaling proteins by DIDS.

DIDS inhibits the activation of caspases induced by staurosporine It has been shown that chloride flux ${ }^{5}$ and VDAC ${ }^{17,25}$ participate in apoptosis, since their inhibition with DIDS, among other compounds, reduces apoptosis. Indeed, preincubation of HeLa cells with DIDS for $30 \mathrm{~min}$ inhibited STS-induced activation of caspases-3, -9 and -8 (Figure 2). For all the caspases assessed, the low concentration of DIDS $(50 \mu \mathrm{M})$ displayed the maximal inhibitory effect on STS-induced activation of caspases. However, there was a small fraction of caspase- 3 activity (approximately $15 \%)$ that was equally resistant to both 50 and $500 \mu \mathrm{M}$ DIDS (Figure 2a). This was not the case for caspase- 9 and caspase-8 since they were fully blocked by $50 \mu \mathrm{M}$ DIDS (Figures $2 \mathrm{~b}$ and $\mathrm{c}$ ). Unexpectedly, DIDS by itself induced DEVDase activity resistant to the inhibitor of caspase-3 (Ac-DEVD-CHO), increasing by 3-fold with $50 \mu \mathrm{M}$ and by 8 -fold with $500 \mu \mathrm{M}$. The latter was large enough to be significant (Figure 2a). However, this new effect of DIDS was specific for DEVDase since it increased neither LEHDase (caspase-9, Figure 2b) nor IETDase (caspase-8, Figure 2c) activities. It is important to highlight that this DEVDase activity resistant to the caspase-3 inhibitor was only induced by DIDS; because other ion channel inhibitors like flufenamic acid or 2-APB (that inhibit apoptosis; Supplementary Figure S3) did not increase DEVDase activity. These data suggest that DIDS $(50 \mu \mathrm{M})$ inhibits activation of both initiator and execution caspases and that DIDS at high concentrations $(500 \mu \mathrm{M})$ induced a new DEVDase activity that was resistant to the caspase- 3 inhibitor.

DIDS did not inhibit STS-induced cytochrome $c$ release

The inhibitory effect of DIDS on caspase- 9 activity might suggest that this agent affects apoptosis by blocking upstream events of caspase activation. In this regard, we studied the effect of DIDS on STS-induced cytochrome $c$ release in HeLa cells that had been without serum for $24 \mathrm{~h}$ and used tubulin as a loading control (Figure 3a). To this end, cells were lysed and the supernatant separated by centrifugation at $10000 \times g$ for western blot. The protein content of these fractions was not affected by incubation with STS (Supplementary Figure S4). Neither 50 nor $500 \mu \mathrm{M}$ DIDS significantly reduced STS-induced cytochrome $c$ release that was normalized against tubulin, if anything there was only a slight reduction (Figure $3 b, n=7$ ). Interestingly, high concentrations of DIDS $(500 \mu \mathrm{M})$ alone induced to some extent release of cytochrome c (Figure 3). We have determined that the effect of STS on cytochrome $c$ release was not blocked by either a pancaspase inhibitor $^{26}$ or $1 \mu \mathrm{M}$ cyclosporine $\mathrm{A}$ (not shown), the latter to inhibit activation of the mitochondrial permeability transition

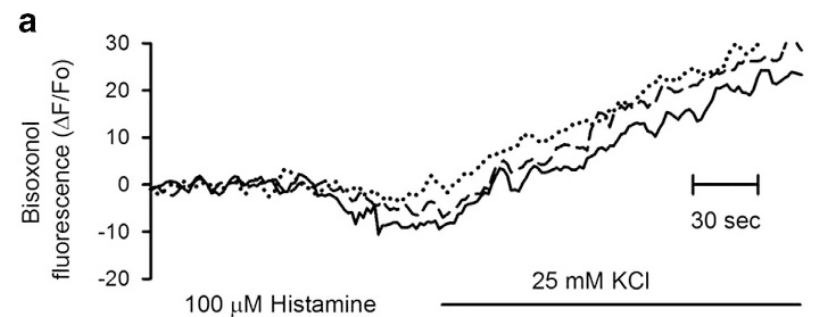

b
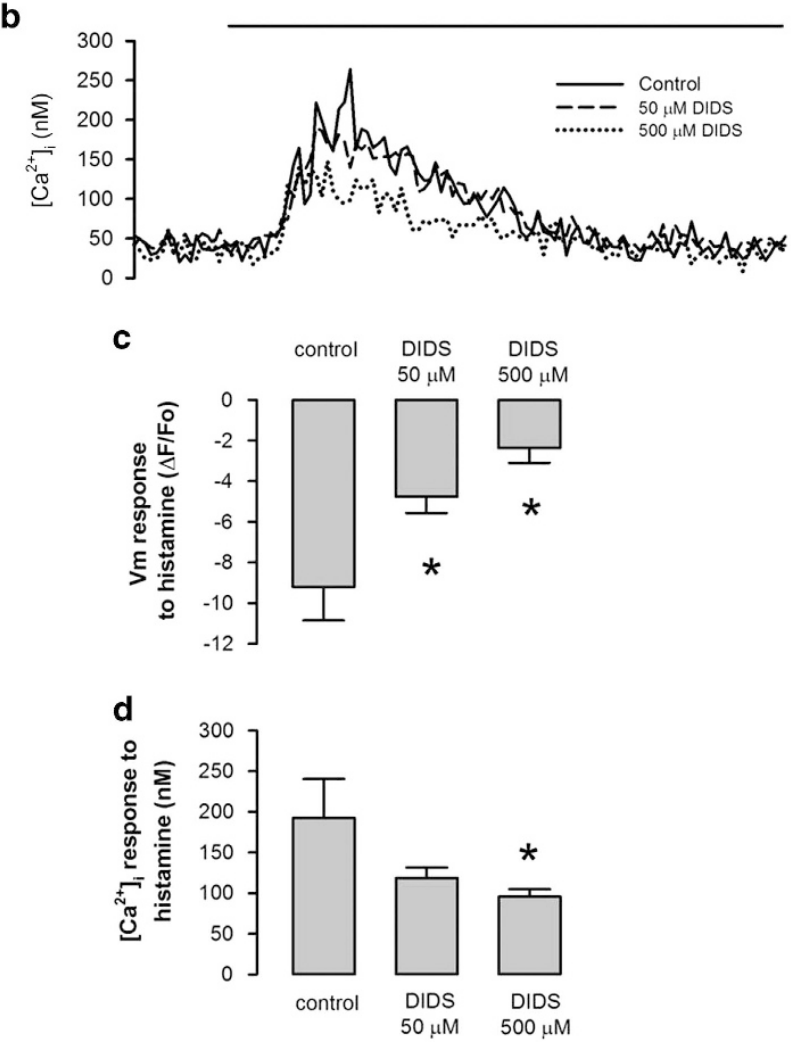

Figure 1. DIDS irreversibly alters histamine-induced PMP and $\left[\mathrm{Ca}^{2+}\right]_{\text {in }}$ responses in HeLa cells. Simultaneous recordings of the effect of DIDS preincubation on plasma membrane potential (PMP) (a) and $\left[\mathrm{Ca}^{2+}\right]_{\mathrm{i}}(\mathbf{b})$ in response to histamine and elevation of external $\left[\mathrm{K}^{+}\right]$ (applied where indicated). Representative recordings in DIDS-free saline solution of cells that had been preincubated without (solid line) or with DIDS 50 (dashed line) or $500 \mu \mathrm{M}$ (dotted line) for $2 \mathrm{~h}$. Note that histamine induced membrane hyperpolarization (a), as a result of the activation of $\mathrm{Ca}^{2+}$-dependent $\mathrm{K}^{+}$channels by the histamine-induced $\left[\mathrm{Ca}^{2+}\right]_{\mathrm{i}}$ response (b). Preincubation of cells with either 50 or $500 \mu \mathrm{M}$ DIDS decreased histamine-induced PMP response (c) while only $500 \mu \mathrm{M}$ DIDS reduced histamine-induced $\left[\mathrm{Ca}^{2+}\right]_{\mathrm{i}}$ response $(\mathbf{d}) .(n=3, * P<0.05)$.

pore. However, we have shown that high external $\left[\mathrm{K}^{+}\right]$or the combination of $\mathrm{K}^{+}$channels blockers such as $\mathrm{TEA}^{+}$and $4 \mathrm{AP}$ significantly inhibited STS-induced cytochrome $c$ release. ${ }^{26}$ These data suggest that DIDS inhibits caspase activation downstream of cytochrome c release in STS-induced apoptosis of HeLa cells.

DIDS directly inhibits caspase activity in cell lysates

Because DIDS did not inhibit STS-induced cytochrome c release, yet fully blocked activation of caspases, particularly caspase-9; we decided to study whether DIDS had any direct inhibitory effect on caspases. To this end, we incubated cells with STS for $4 \mathrm{~h}$ and prepared cell lysates that contain fully activated caspases. These lysates were further incubated with $50 \mu \mathrm{M}$ DIDS for $45 \mathrm{~min}$ at $32^{\circ} \mathrm{C}$ and the remaining caspase activities were assessed. In all cases, 
this procedure led to complete inhibition of previously activated caspases-3, -9 and -8 (Figure 4). Incubation of these cell extracts with other ion channel blockers, for example, 2-APB $(50 \mu \mathrm{M})$ a nonspecific inhibitor of ion channels including; $\mathrm{IP}_{3} \mathrm{R}_{1}{ }^{27} \mathrm{Orai}^{28}$ and TRPM2 channel ${ }^{29}$ or flufenamic acid $(50 \mu \mathrm{M})$ an inhibitor of $\mathrm{Cl}^{-}$and cation channels, ${ }^{30}$ did not have any effect on the previously activated caspase-3 (Figure 4a). Collectively, these data imply that
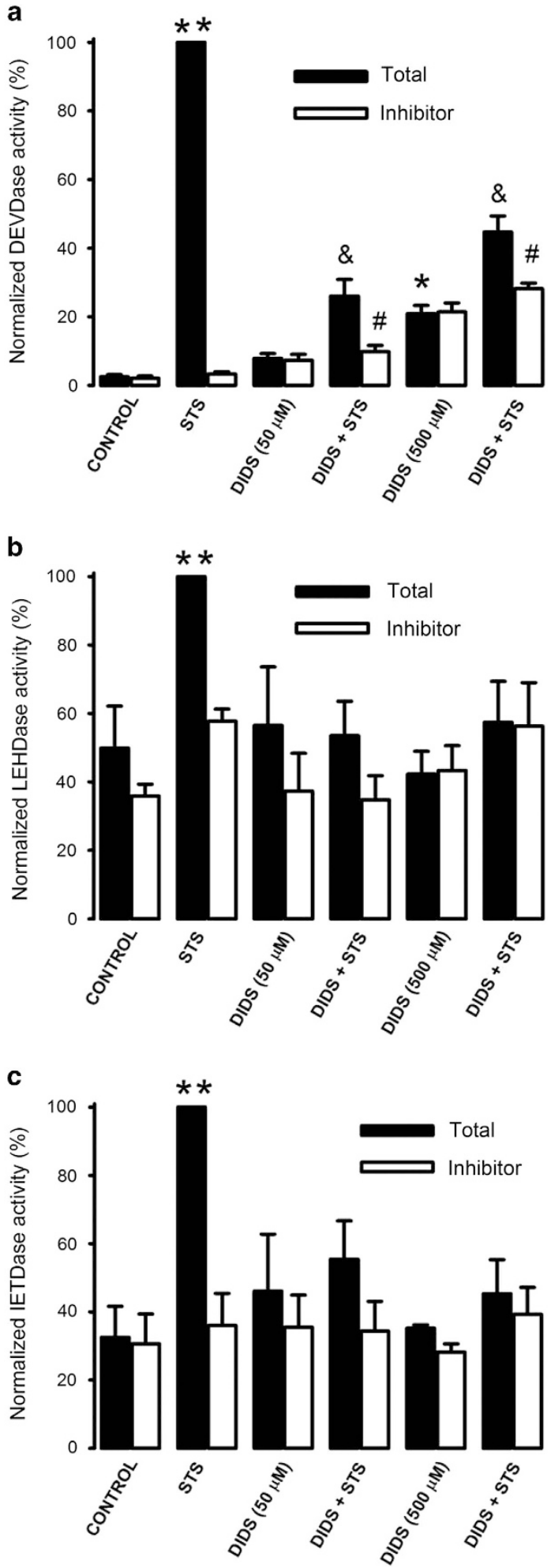

DIDS can directly inhibit the activity of caspases by a mechanism that is unrelated to the blocking effect of this substance on the activity of $\mathrm{Cl}^{-}$transport and VDAC.

DIDS inhibits STS-induced procaspase- 3 processing, caspase-3 substrate degradation and apoptotic nuclei

To verify that DIDS has an inhibitory effect on initiator caspases and caspase-3, we studied the effect of DIDS on the processing of procaspase- 3 and the cleavage of a known substrate of caspase-3 by western blot assays. As expected, STS produced a complete processing of procaspase- $3(35 \mathrm{kDa})$, a situation that was strongly inhibited by preincubating the cells with either 50 or $500 \mu \mathrm{M}$ DIDS (Figure 5a). Accordingly, STS was able to generate a cleaved form of caspase-3 (17-19 kDa). The amount of this fragment was
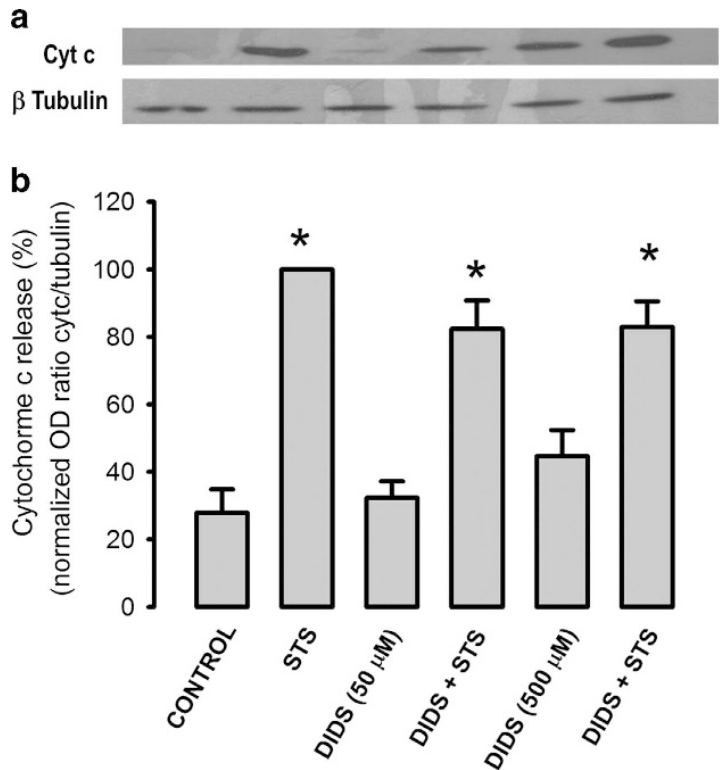

Figure 3. DIDS does not abolish STS-induced cyt $\mathrm{c}$ release. HeLa cells that were in the absence of serum for $19.5 \mathrm{~h}$ were preincubated with or without DIDS $(50$ or $500 \mu \mathrm{M})$ for 30 min followed by STS $(1 \mu \mathrm{M})$ incubation for $4 \mathrm{~h}$ and lysed to determine cytochrome $\mathrm{c}$ release from mitochondria. (a) Representative western blots of cytochrome c (cyt c) and p tubulin in supernatants of cell lysates. Note that DIDS $500 \mu \mathrm{M}$ release some cyt c by itself. (b) The optical density ratio between signals of cyt $c$ and p-tubulin was normalized using the STS-induced ratio as $100 \%$. DIDS did not inhibit cytochrome c release, only reduced it by $20 \%$ at both concentrations of DIDS $(n=7)$. ${ }^{*} P<0.05$ between staurosporine-induced ratio and the corresponding control condition.

Figure 2. DIDS inhibits STS-induced caspase activation in HeLa cells. Cells that were preincubated with or without DIDS $(50$ or $500 \mu \mathrm{M})$ for 30 min were incubated with STS $1 \mu \mathrm{M}$ for $4 \mathrm{~h}$ and lysed to determine caspase activity, which was normalized based on the response obtained with STS. Panels show caspase-3 $(\mathbf{a}, n=7)$, capase-9 (b, $n=4)$ and caspase-8 (c, $n=4)$ activities without (total activity, solid columns) and with caspase inhibitors (open columns), which were Ac-DEVD-CHO for caspase-3 (a), Ac-LEHD-CHO for caspase-9 (b) and Ac-IETD-CHO for capase-8 (c).In all cases, STS induced a significant caspase activity with respect to control ${ }^{* *} P<0.05$ ). ${ }^{*}, \&, \# P<0.05$, Tukey multiple comparison test. ${ }^{*}$ DIDS $500 \mu \mathrm{M}$ increased DEVDase activity unrelated to caspase- 3 when compared with control activity. ${ }^{8}$ STS-induced caspase-3 activity is significantly smaller in the presence of either 50 or $500 \mu \mathrm{M}$ DIDS. "There is a small but significant caspase- 3 activity resistant to DIDS. 

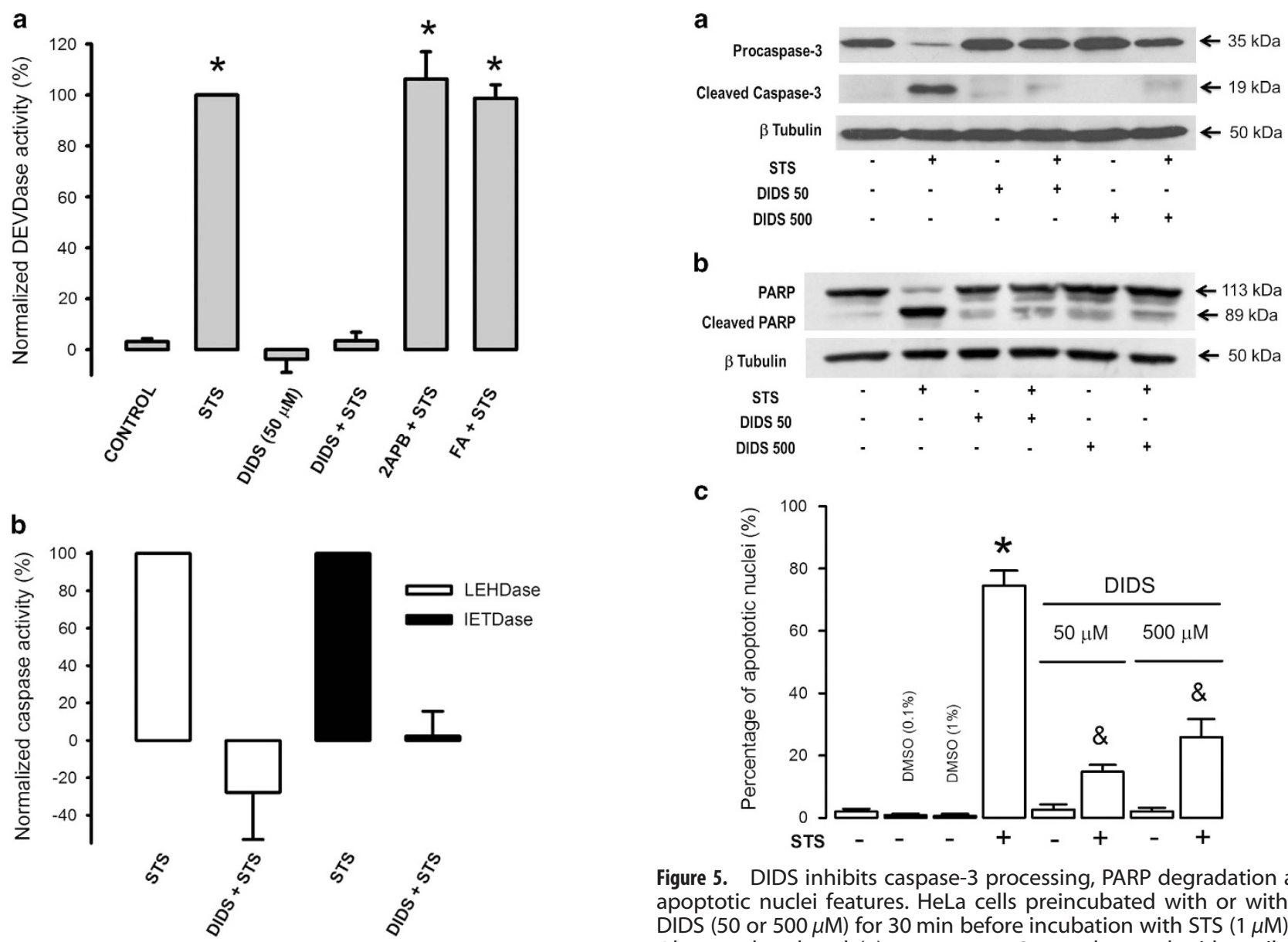

c

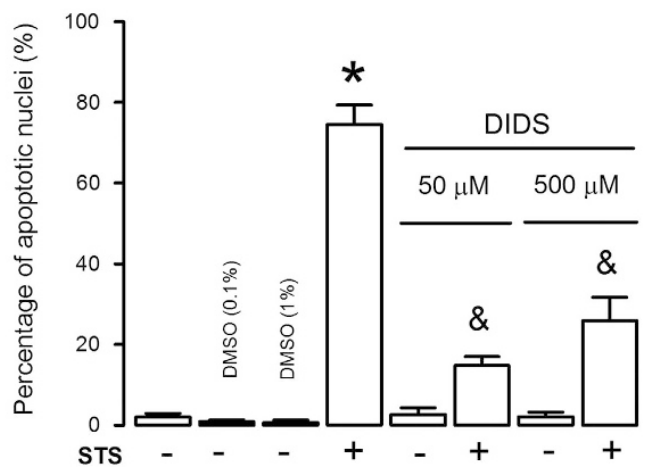

Figure 5. DIDS inhibits caspase-3 processing, PARP degradation and apoptotic nuclei features. HeLa cells preincubated with or without DIDS $(50$ or $500 \mu \mathrm{M})$ for 30 min before incubation with STS $(1 \mu \mathrm{M})$ for $4 \mathrm{~h}$ were lysed and (a) pro-caspase 3 was detected with antibody (clone $3 G 2, n=3$ ) and (b) PARP fragmentation with antibody (clone 4C 10-5, $n=5$ ). DIDS totally abolished procaspase-3 proteolytic processing and strongly diminished STS-induced PARP fragmentation. (c) Apoptotic nuclei were induced by STS ( $4 \mathrm{~h}$ incubation). However, neither the vehicle (DMSO, 0.1 or $1 \%$ ) nor DIDS alone induced apoptotic nuclei. Preincubation with DIDS $(50 \mu \mathrm{M})$ strongly inhibited STS-induced apoptotic nuclei features. Interestingly, this inhibitory effect was a little bit smaller for a 10 times higher concentration of DIDS $(500 \mu \mathrm{M}){ }^{*} \& P<0.05$, Tukey multiple comparison test. *respect the control, \& respect the effect of STS.

strongly diminished by the preincubation with DIDS (Figure $5 \mathrm{a}$, $n=3$ ). PARP enzyme has been shown to be one of the substrates of caspase- $3,{ }^{31}$ as expected STS induced cleavage of PARP from the original $113 \mathrm{kDa}$ to a smaller fragment of $89 \mathrm{kDa}$. This effect was dramatically reduced by preincubation of cells with either 50 or $500 \mu \mathrm{M}$ DIDS (Figure 5b, $n=5$ ). Additionally, we have studied the effect of STS alone and in combination with DIDS on the nuclear morphology using confocal microscopy (Supplementary Figure S5). Control cells, which had been in the absence of serum for $24 \mathrm{~h}$, showed normal nuclear morphology that was not altered by either DMSO vehicle ( 0.1 or $1 \%)$ or DIDS alone (50 or $500 \mu \mathrm{M})$. However, STS ( $1 \mu \mathrm{M}$ for $4 \mathrm{~h}$ ) induced on average $75 \%$ of apoptotic nuclei. DIDS $(50 \mu \mathrm{M})$ inhibited this effect since only $15 \%$ nuclei showed apoptotic features. Increasing the DIDS concentration $(500 \mu \mathrm{M})$ did not result in higher inhibition, if anything, a slightly decreased effect was now observed with $25 \%$ of the nuclei showing apoptotic characteristics (Figure 5c). Collectively, these data suggest that DIDS ( $50 \mu \mathrm{M})$ inhibits STS-induced procaspase-3 processing, PARP degradation and apoptotic nuclear features. Increasing the DIDS concentrations $(500 \mu \mathrm{M})$ did not augment any of these parameters. Actually, this higher concentration showed signs of some deleterious effects.

\section{DIDS permeability in HeLa cells}

Our previous data suggest that DIDS binds to proteins in an irreversible manner as it has been shown in other systems. ${ }^{15}$ To corroborate this situation, we took advantage of the fluorescent properties of DIDS. ${ }^{32}$ We carried out fluorescence spectra at different concentrations of DIDS, exciting at $345 \mathrm{~nm}$ wavelength and detecting fluorescence at $420 \mathrm{~nm}$ wavelength, we observed a concentration-dependent increase in DIDS fluorescence up to $50 \mu \mathrm{M}$; at $500 \mu \mathrm{M}$ DIDS fluorescence decreased most likely by a process known as internal quenching (Figure 6a), making it difficult to assess the concentration at high levels with the use of fluorescence; however, fluorescence can be used to estimate concentrations lower than $50 \mu \mathrm{M}$ DIDS under our recording conditions. Accordingly, HeLa cells were preincubated with 5, 50 and $500 \mu \mathrm{M}$ DIDS for at least $1 \mathrm{~h}$ and then thoroughly washed before recording their fluorescence. DIDS at $5 \mu \mathrm{M}$ did not significantly increase HeLa cell fluorescence; however, 50 and $500 \mu \mathrm{M}$ DIDS increased cell fluorescence (Figure 6b), the former increased HeLa cell fluorescence to levels comparable to an aqueous solution of $5 \mu \mathrm{M}$ DIDS. Since we used only 300000 cells per $\mathrm{ml}$ of recording solution, we think it is unlikely that all the DIDS 

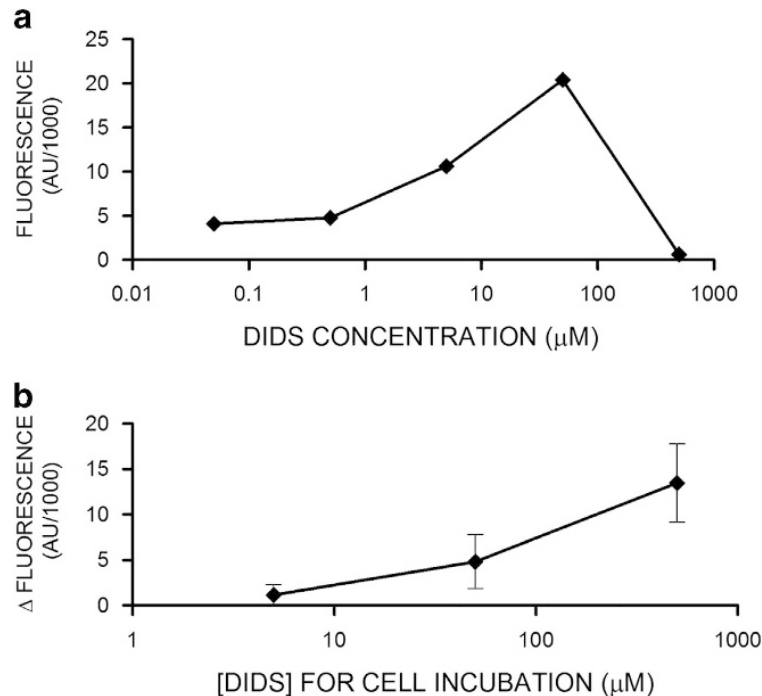

Figure 6. DIDS binds irreversibly to HeLa cells and make them fluorescent. (a) DIDS fluorescence signal as a function of concentration shows a biphasic behavior. DIDS concentrations higher than $50 \mu \mathrm{M}$ displayed a reduction in fluorescence signal most likely due to internal quenching. (b) HeLa cells preincubated with DIDS $(5,50$ or $500 \mu \mathrm{M})$ for $2 \mathrm{~h}$ were washed and fluorescence due to DIDS $(420 \mathrm{~nm})$ was determined $(n=3)$. HeLa cells autofluorescence was substracted from the signal obtained for those preincubated with DIDS. Collectively, these data suggest that preincubating cells with $50 \mu \mathrm{M}$ DIDS leads to an accumulation of this inhibitor of at least $5 \mu \mathrm{M}$ inside cells.

is packed in the plasma membrane, mainly because we expect that this packaging of DIDS at the plasma membrane would quench DIDS fluorescence. It seems feasible that a large fraction of DIDS is internalized and bound to cell proteins arguing for the idea that under our incubation conditions $\left(37^{\circ} \mathrm{C}\right.$ for $\left.4.5 \mathrm{~h}\right)$ DIDS has been incorporated into HeLa cells reaching internal proteins. To verify this conclusion, we have carried out confocal microscopy studies of DIDS cellular localization. Control cells did not show any fluorescent signal excited at $405 \mathrm{~nm}$ (Figure 7a). Cells incubated with DIDS $(50 \mu \mathrm{M})$ for $2 \mathrm{~h}$ displayed a stained plasma membrane and also a vesicular structure located close to the nucleus (Figure 7b). Cells in $500 \mu \mathrm{M}$ DIDS displayed a higher fluorescence signal both at the periphery and inside cells (Figure 7c). These data suggest that DIDS binds to cells and internalizes in an irreversible manner because these cells were thoroughly washed to remove unbound DIDS before fixation.

\section{DISCUSSION}

We have found in this study that DIDS was unable to inhibit cytochrome c release in HeLa cells that had been in the absence of serum for $24 \mathrm{~h}$ and exposed to STS for only $4 \mathrm{~h}$. These data suggest that there is another target for DIDS downstream of the mitochondrial stage of apoptosis, and that this new target is not an anion transporter. We have demonstrated that DIDS at $50 \mu \mathrm{M}$, totally and directly inhibits previously activated caspases-3, -9 and -8 in cell lysates. However, under our experimental conditions, the effect appears to be more complex, since in cells, there is a small fraction of caspase- 3 that was resistant to DIDS and high concentrations of DIDS $(500 \mu \mathrm{M})$ induced a DEVDase activity that cannot be ascribed to caspase 3 because it was not inhibited by its corresponding inhibitor. Interestingly, it has been reported that DIDS $(500 \mu \mathrm{M})$ fully inhibits STS-induced apoptosis, while having no effect on etoposide- or TNF-induced cell death in Jurkat cells. ${ }^{14}$
AVD appears to have an important role in some forms of apoptosis, ${ }^{5}$ because the reduction of intracellular concentrations of both $\mathrm{K}^{+}$and $\mathrm{Cl}^{-}$ions, via different types of ion channels or transporters, is required for the activation of caspases. In this regard, it has been shown that different types of inhibitors of either $\mathrm{K}^{+}$or $\mathrm{Cl}^{-}$flux inhibit apoptosis to some extent. ${ }^{2,4}$ Accordingly, DIDS has frequently been used as an inhibitor of either $\mathrm{Cl}^{-}$channels ${ }^{3}$ or $\mathrm{Cl}^{-} / \mathrm{HCO}_{3}^{-}$exchanger, ${ }^{15}$ and inhibits AVD produced by different and unrelated apoptosis inducers such as STS, TNF, etoposide, dexametasone, serum removal and hypoxia. ${ }^{5,14}$ This effect of DIDS on AVD is also shared by many other inhibitors of $\mathrm{Cl}^{-}$transport such as NPPB and SITS. ${ }^{5}$ All these inhibitors also reduced cell death regardless of the inducer used. ${ }^{5}$ Interestingly, there are some cases where DIDS blocks apoptosis more strongly than the other $\mathrm{Cl}^{-}$transport inhibitors such as NPPB or SITS, $8,11,12,14,33$ or even $\mathrm{K}^{+}$channel blockers like quinine. ${ }^{8}$ Together, these data suggest that DIDS might have another target in cells besides $\mathrm{Cl}^{-}$transporters and this might explain why DIDS is a generalized inhibitor of apoptosis.

It has been reported that dissolving DIDS in water produces reaction of its isothiocyanate reactive groups $(-N=C=S)$ to form amino groups, which in turn can react with intact DIDS to form multimers that become a large impermeable multianion molecule due to the accumulation of sulfonate groups $\left(-\mathrm{SO}_{3}^{-}\right)$in the multimer. ${ }^{34}$ Importantly, our stock solution of DIDS was dissolved in dehydrated DMSO. We think that this situation should decrease the probability of multimer formation. Accordingly, cells were incubated with monomeric, permeable and reactive DIDS. In this regard, we observed that cells incubated with DIDS and washed twice (to eliminate the unbound DIDS before the incubation with $\mathrm{Ca}^{2+}$ and PMP indicators) had reduced histamine-induced responses in both $\left[\mathrm{Ca}^{2+}\right]_{i}$ and PMP hyperpolarization. These data indicate that DIDS modifies irreversibly cellular responses. Moreover, cell fluorescence due to the presence of DIDS was increased in these washed cells concentration dependently, arguing for DIDS incorporation into cells, because the packing of all this DIDS in the plasma membrane should not fluoresce due to internal quenching. Indeed, we were able to image DIDS inside cells and most likely attached to internal proteins.

Another target of DIDS is VDAC, a voltage-dependent anion channel that participates in cytochrome $c$ release induced by different apoptotic stimuli. ${ }^{17,25,35}$ In this regard, DIDS inhibits mitochondrial membrane depolarization triggered by different inducers of apoptosis; this inhibition involves a mechanism that depends on VDAC. ${ }^{8,12,16}$ These data imply that DIDS reaches the interior of cells to interact with VDAC in the outer mitochondrial membrane to inhibit both cytochrome $c$ release and mitochondrial membrane depolarization. Accordingly, cytochrome $c$ release triggered by different type of apoptosis inducers, and in different cell types was strongly inhibited by DIDS. 5, 16,25,35 However, this effect of DIDS on cytochrome $c$ release was not always mimicked by other $\mathrm{Cl}^{-}$channel inhibitors, such as NPPB ${ }^{12,14}$ indicating that only DIDS may have an effect on VDAC. Importantly, our data have shown that STS-induced cytochrome $c$ release in HeLa cells that had been in the absence of serum for $24 \mathrm{~h}$ cannot be blocked by DIDS, suggesting that in this case cytochrome c release does not depend on VDAC (not more than 20\%).

Certainly, there are reports showing an inhibitory effect of DIDS in apoptosis that cannot be explained by DIDS blocking cytochrome c release; ${ }^{11,36}$ which is also the case shown here. This implies that DIDS is inhibiting apoptosis by a mechanism downstream to cytochrome c release. ' A currently overlooked action of DIDS in the field of apoptosis is its well-described activity as an alkylating agent, where isothiocyanate groups have a key part in this effect. Isothiocyanate groups can react with both amino and thiol groups, ${ }^{21}$ the latter are the reactive groups in the active site of all caspases. Since DIDS contains two reactive isothiocyanate groups, we think that one of these groups is 

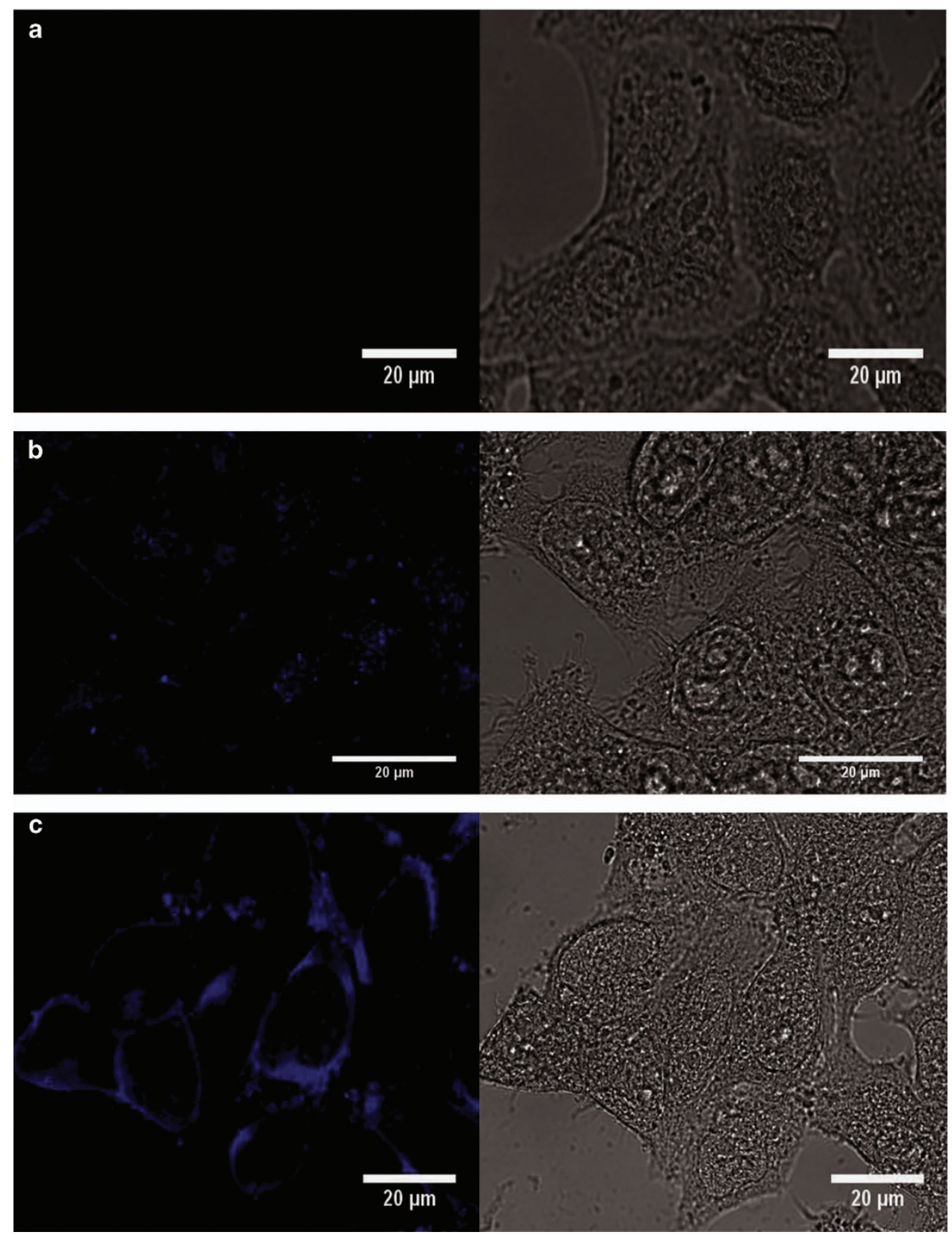

Figure 7. Confocal imaging of DIDS-labeled HeLa cells. (a) Control cells, because were not incubated with DIDS, display no fluorescence signal. (b) HeLa cells that were incubated with $50 \mu \mathrm{M}$ DIDS showed labeling of cell periphery and a vesicular structure that is located in close proximity to the nucleus. (c) Higher concentrations of DIDS $(500 \mu \mathrm{M})$ produced a fluorescent signal of larger intensity particularly at the cell periphery but also inside cells. Importantly, bright field image of HeLa cells with $500 \mu \mathrm{M}$ DIDS do not look as healthy as control cells. These cells show some donut-shaped structures that are stained by DIDS.

reacting with the thiol group inactivating the protease, while the other might keep DIDS close to the active site by reacting with lysines nearby. In this regard, Lys 53, 57 and 210 are located close to the active site according to the human caspase-3 crystal structure. $^{37}$ This scenario is supported by the observation that DIDS completely inhibited all caspases examined (capase-3, caspase- 8 and caspase-9), in cell lysates containing previously activated caspases. However, cells incubated with DIDS displayed a complex pattern of inhibition, particularly for caspase-3. In short, $50 \mu \mathrm{M}$ DIDS inhibited $85 \%$ of STS-induced caspase-3 activity in cells. This means that there is $15 \%$ caspase- 3 activity resistant to DIDS and this situation was not concentration dependent since $500 \mu \mathrm{M}$ DIDS did not change this percentage, although noise was reduced and the difference became significant. Caspase-3 resistant to DIDS might be the one located in the nucleus, where the presence of histones, proteins rich in lysine, would quench the alkylating effect of DIDS on caspase-3. This type of scenario might explain this observation because we could not find any caspase-3 activity resistant to DIDS in the cell-free extract. Importantly, this small fraction of caspase- 3 resistant to DIDS was not observed in western blot, and we think that the explanation is that we used only supernatants to assess the cleavage of procaspase- 3 . Interestingly, it has been shown that DIDS at $500 \mu \mathrm{M}$ fully inhibited STS-induced apoptosis, while it had no effect on etoposide-induced apoptosis in Jurkat cells. ${ }^{14}$ It appears also that the mitochondrial transition pore was not involved; because 
cyclosporine A did not have any effect on the apoptosis triggered by either of the two inducers. ${ }^{14}$ Whether these data could be explained by etoposide activating a DIDS-resistant caspase-3 in Jurkat cells, might be interesting to look into. Moreover, it was completely unexpected to find that DIDS at high concentrations $(500 \mu \mathrm{M})$ induced a DEVDase activity that cannot be ascribed to caspase-3, since this was not blocked by the caspase- 3 inhibitor. We did not study this activity any further, so we do not have any indication regarding the nature of this protease activated by DIDS. Interestingly, it has recently been reported that DIDS induces apoptosis in neurons as a consequence of increasing the expression of caspase-3. ${ }^{38}$ It is plausible that the ability of DIDS to stimulate a new DVEDase activity might explain why DIDS is not always protective either with long incubation times or at high concentrations.

In summary, DIDS besides the inhibition of anion channels both at the plasma membrane and in the mitochondria that might suffice to explain its inhibitory action in apoptosis can also inhibit the activity of caspases most likely by alkylating the reactive thiol group in the active site of these proteases. The latter might explain why DIDS is a generalized inhibitor of apoptosis when compared with other anion channel inhibitors. In fact, flufenamic acid did not have any effect on caspase-3 activity in cell-free extracts.

\section{CONCLUSION}

Our work can be better explained based on previous observations that DIDS alkylates both thiol and amino groups in proteins and we propose that this is the reason for DIDS directly inhibiting caspase activity, in both intact and lysed cells. Our data suggest that $50 \mu \mathrm{M}$ DIDS is enough to inhibit STS-induced apoptosis and that higher concentrations $(500 \mu \mathrm{M})$ might have deleterious effects, probably because it induces a new DEVDase activity that is resistant to the caspase- 3 inhibitor. This newly discovered action of DIDS to directly inhibit caspases, together with the other wellestablished actions of DIDS, such as inhibition of $\mathrm{Cl}^{-}$fluxes and cytochrome c release via VDAC, might explain why DIDS is able to block staurosporine-induced apoptosis much better than other ion channel inhibitors.

\section{MATERIALS AND METHODS}

\section{Materials}

Cell culture reagents were obtained from Gibco-Invitrogen (Grand Island, NY, USA). DIDS, staurosporine (STS), histamine, 2-Aminoethyl diphenylborinate (2-APB), flufenamic acid, gramicidin (Gram), Ac-DEVD-AMC (caspase-3 substrate), Ac-DEVD-CHO (caspase-3 inhibitor), Ac-LEHD-AFC (caspase-9 substrate), Ac-IETD-CHO (caspase-8 inhibitor), DMSO, Hoechst 33258 and protease inhibitor cocktail were purchased from Sigma-Aldrich (St. Louis, MO, USA). Ac-IETD-AMC (caspase-8 substrate) was obtained from Enzo Life Sciences (Lausen, Switzerland). Fura2-AM and $\mathrm{DiBaC}_{4}$ (3) (Bisoxonol) were obtained from Invitrogen (Molecular Probes, Eugene, OR, USA). z-VAD-fmk was purchased from Promega (Madison, WI, USA). Mouse anti-cytochrome c monoclonal antibody (Clone $7 \mathrm{H} 8.2 \mathrm{C} 12$ ) and mouse anti-human PARP (Clone 4C10-5) were purchased from BD-Pharmingen (Chicago, IL, USA). Mouse anti-Caspase-3 (Clone 3G2) was obtained from Cell Signaling (Danvers, MA, USA). Mouse anti- $\beta$-tubulin was acquired from ZYMED (Carlsbad, CA, USA). Importantly, DIDS was prepared as a 50-mM stock in dehydrated DMSO, to avoid the hydrolysis of isothiocyanate groups. ${ }^{34}$ In control studies, $1 \%$ dehydrated DMSO neither induced caspase- 3 activity nor blocked STS-induced caspase-3 activity (Supplementary Figure S6).

\section{Cell culture}

HeLa cells were cultured in Dulbecco's modified Eagle's medium with high D-glucose $(4.5 \mathrm{~g} / \mathrm{L})$, L-glutamine and sodium pyruvate $(110 \mathrm{mg} / \mathrm{L})$ and supplemented with both $5 \%$ fetal bovine serum and 3\% newborn calf serum and with the antibiotic $1 \%$ penicillin/streptomycin. Cells were maintained at $37^{\circ} \mathrm{C}, 5 \% \mathrm{CO}_{2}$ and constant humidity. Serum was removed from the cells $24 \mathrm{~h}$ before commencing any experiment. These cells were then either induced to undergo apoptosis with staurosporine (STS), they were used to monitor changes in the plasma membrane potential (PMP) and $\left[\mathrm{Ca}^{2+}\right]_{i}$, or they were incubated with DIDS to determine cell-associated DIDS fluorescence.

\section{Simultaneous determination of PMP and $\left[\mathrm{Ca}^{2+}\right]_{\mathrm{i}}$}

After $24 \mathrm{~h}$ without serum, confluent HeLa cells were incubated with DIDS ( 50 or $500 \mu \mathrm{M}$ ) or without for $2 \mathrm{~h}$, then the cells were harvested, washed to remove unbound DIDS and the cell pellet was resuspended in saline solution containing (in mM): $121 \mathrm{NaCl}, 5.4 \mathrm{KCl}, 0.8 \mathrm{MgCl}_{2}, 1.8 \mathrm{CaCl}_{2}, 6$ $\mathrm{NaHCO}_{3}$ and 25 Hepes, adjusted to $\mathrm{pH} 7.3$ with $\mathrm{NaOH}^{39}$ at a cell density of $3 \times 10^{6}$ cells $/ \mathrm{ml}$. Cell viability was always $\geqslant 95 \%(0.08 \%$ Trypan Blue exclusion). The cell suspension was incubated with the $\mathrm{Ca}^{2+}$ indicator Fura$2 \mathrm{AM}(1 \mu \mathrm{M}$ per million cells) for $1 \mathrm{~h}$. Thereafter, $250 \mu \mathrm{l}$ of the cell suspension $\left(\sim 7.5 \times 10^{5}\right.$ cells $)$ was centrifuged to remove the extracellular Fura-2. The cells were resuspended in a cuvette with $2.5 \mathrm{ml}$ of saline solution which contained $125 \mathrm{nM}$ bisoxonol (PMP indicator). Dye loaded cells were sequentially excited at 340,360 and $380 \mathrm{~nm}$ (for Fura-2) and $480 \mathrm{~nm}$ (for bisoxonol) and the emitted fluorescence signal collected at $530 \mathrm{~nm}$ using a QM-8 spectrofluorometer (PTI, Edison, NJ, USA). Once the bisoxonol fluorescence had leveled off, this signal was calibrated in $\mathrm{mV}$ by increasing the $\mathrm{K}^{+}$conductance with histamine $(100 \mu \mathrm{M})$ followed by five consecutive additions of $\mathrm{KCl}(25 \mathrm{mM}$ each time) and finally gramicidin $(1 \mu \mathrm{M})$ to fully depolarized the cells, as previously described. ${ }^{25}$ However, since there is no certainty that histamine produced complete hyperpolarization in those cells incubated with DIDS, $\Delta \mathrm{F} / \mathrm{Fo}$ data were not converted to $\mathrm{mV}$. The Fura-2 signal was calibrated by applying digitonin $(112 \mu \mathrm{M})$ to obtain $R_{\text {max }}$ followed by EGTA $(10 \mathrm{mM})$ to obtain $R_{\min }$ and finally $\mathrm{MnSO}_{4}$ addition $(9 \mathrm{mM})$ to obtain a measure of the autofluorescence. Fluorescence signals were acquired and analyzed with Felix 32 software (PTI).

\section{STS induction of caspase activity}

HeLa cells were cultured in 6-well plates in the absence of serum for $24 \mathrm{~h}$ to enhance caspase-3 activation by STS (Supplementary Figure S7). To study the effect of DIDS, HeLa cells without serum for $19.5 \mathrm{~h}$ were preincubated with DIDS $(50$ or $500 \mu \mathrm{M})$ for $30 \mathrm{~min}$ followed by the addition of STS $(1 \mu \mathrm{M})$ for an additional $4 \mathrm{~h}$ at $37^{\circ} \mathrm{C}$. To assess caspase activity, the culture medium was removed and added $500 \mu \mathrm{l}$ caspase lysis buffer to each well $(50 \mathrm{mM}$ Hepes, $5 \mathrm{mM}$ DTT and $1 \%$ Triton X-100) and the plate was kept on ice with gentle shaking for $30 \mathrm{~min}$ before collecting the lysates.

\section{Determination of caspase activity}

Determination of caspase-3 activity. Assays were carried out according to the specifications in the kit with slight modifications as previously described. ${ }^{26}$ Briefly, caspase-3 assay buffer contained in mM: 20 Hepes, 5 DTT, 2 EDTA and $0.1 \%$ Triton X-100, pH 7.4. For each one of the determinations, the assay buffer was supplemented with $50 \mu \mathrm{L}$ of the cell lysate and $1 \mu \mathrm{M}$ Ac-DEVD-AMC (caspase-3 substrate) with or without $2 \mu \mathrm{M}$ Ac-DEVD-CHO (caspase-3 inhibitor). These mixes were incubated at room temperature for $90 \mathrm{~min}$. Caspase-3 activity was determined by subtracting the fluorescence signal obtained with the combination of substrate and inhibitor from the one with only substrate. The corrected signal obtained from cells incubated with STS was taken as $100 \%$ response. Figure 2 shows the fluorescence signal with substrate alone (closed columns) and the one obtained with the combination of substrate plus inhibitor (open columns) to demonstrate that $500 \mu \mathrm{M}$ DIDS induced a new DEVDase activity that was not blocked by caspase-3 inhibitor.

Determination of caspase-9 activity. The assay was carried out as previously described ${ }^{40}$ with slight modification. Caspase- 9 assay buffer contained in mM: 100 MOPS, 10 DTT, 0.5 EDTA, 0.1\% Triton X-100, pH 6.5 and $10 \%$ glycerol. The assay buffer with $100 \mu \mathrm{l}$ of the cell lysate was preincubated for $30 \mathrm{~min}$ at $32^{\circ} \mathrm{C}$ before supplementing it with $1 \mu \mathrm{M}$ Ac-LEHD-AFC (caspase-9 substrate), either in the presence or in the absence of $2 \mu \mathrm{M}$ Ac-LEHD-CHO (caspase-9 inhibitor) and further incubated at $32^{\circ} \mathrm{C}$ for $24 \mathrm{~h}$. The fluorescence signal was analyzed as for the caspase-3 assay.

Determination of caspase-8 activity. The assay was carried according to the kit instructions with slight modification. Caspase-8 assay buffer 
contained in mM: 20 Hepes, 5 DTT, EDTA, 5\% Sucrose and 0.1\% Triton $\mathrm{X}-100$ at $\mathrm{pH}$ 7.4. The assay buffer was supplemented with $1 \mu \mathrm{M}$ Ac-IETDAMC (caspase-8 substrate) with or without $2 \mu \mathrm{M}$ Ac-IETD-CHO (caspase-8 inhibitor) and $50 \mu \mathrm{l}$ of cell lysate. This mix was incubated at $32{ }^{\circ} \mathrm{C}$ for $24 \mathrm{~h}$. The fluorescence signal was analyzed as for the caspase-3 assay.

Determination of the effect of DIDS on cell lysates

We obtained cell lysates using caspase lysis buffer from HeLa cells that had been previously incubated with STS for $4 \mathrm{~h}$, a time selected because it induces maximal activity of caspases-3, -9 and -8 . To test the direct effect of DIDS on caspase activity, we have previously activated caspases with STS and made cell lysates as described in the section of STS-induction of caspase activity. DIDS $(50 \mu \mathrm{M})$ was added to caspase activity assays and incubated at $37^{\circ} \mathrm{C}$ for $45 \mathrm{~min}$, this was followed by the addition of the corresponding caspase substrate to assess caspase activity as previously described.

Immunodetection of cytochrome c release, PARP fragmentation and procaspase- 3 processing

Cells cultured in 6-well plates were treated as previously described in the caspase activity section ( $24 \mathrm{~h}$ without serum, followed by treatment with STS alone or in the presence of DIDS). The cells were then washed with icecold PBS supplemented with the protease inhibitor cocktail and harvested with a cell lifter. The cell suspension was mechanically lysed by vortexing at top speed until the sample looked foamy $(\sim 30 \mathrm{~s})$. Lysates were then centrifuged at $10^{4} \times \mathrm{g}$ for $30 \mathrm{~min}$ to separate the supernatant (cytosolic fraction) from the pellet (particulate fraction). Thereafter, supernatant protein either $20 \mu \mathrm{g}$ (for cytochrome c and PARP) or $70 \mu \mathrm{g}$ (for procaspase-3) was separated by SDS-PAGE in a discontinuous gradient gel $(5-20 \%$, cytochrome c, PARP) or a continuous gel (16\%, caspase- 3$)$, blotted in PVDF membranes $(0.2 \mu \mathrm{m})$ and revealed with anti-cytochrome $c(1: 1000)$, antiPARP $(1: 1000)$ or anti-caspase-3 $(1: 1000)$. Anti- $\beta$ tubulin $(1: 5000)$ was used as a loading control. We have verified the specificity of the antibodies used with Precision Plus Protein WesternC Standards from Bio-Rad cat 161-0376 (Hercules, CA, USA) as shown in Supplementary Figure S8. Importantly, we did not find any difference in the tubulin level among control cells and those incubated with DIDS with or without STS. In the case of cytochrome $c$, the optical density for each band was divided by the corresponding optical density of $\beta$-tubulin and this ratio obtained for extracts from cells incubated with STS was taken as $100 \%$.

Fluorescence determination of DIDS irreversibly bound to cells To determine the fluorescence properties of DIDS in aqueous solution we put different concentrations (from 50 to $500 \mu \mathrm{M}$ ) of DIDS in a QM-8 spectrofluorometer at $345 \mathrm{~nm} \lambda_{\text {ex }}$ and $420 \mathrm{~nm} \lambda_{\text {em }}$, as previously described ${ }^{32}$ and corrected for background fluorescence of the saline solution.

To estimate the amount of DIDS irreversibly bound to HeLa cells, the cells were incubated with DIDS $(5,50$ or $500 \mu \mathrm{M})$ or without for $2 \mathrm{~h}$ at $37^{\circ} \mathrm{C}$, then washed with DIDS-free PBS and resuspended at a density of $3 \times 10^{6}$ cells $/ \mathrm{ml}$. Approximately $7.5 \times 10^{5}$ of these cells were resuspended in $2.5 \mathrm{ml}$ of saline solution to measure DIDS fluorescence using the wavelengths indicated in the previous paragraph. HeLa cell autofluorescence was subtracted from fluorescence of DIDS-preincubated HeLa cells and this was compared with fluorescence of DIDS in saline solution to estimate the amount of DIDS irreversibly bound to cells.

Imaging of HeLa cells with confocal microscopy

Apoptotic nuclei determination. HeLa cells were grown on coverslips for $24 \mathrm{~h}$ without serum followed by corresponding treatment and fixed for 5 min with Bouin's solution diluted 1:1 with culture media. Coverslips were washed four times with ethanol $70 \%$ and then incubated with Hoechst $33258(5 \mu \mathrm{M})$ overnight. Cell nuclei were analyzed with confocal microscopy (Zeiss LSM 700, Oberkochen, Germany) using a $\times 63$ objective with $405 \mathrm{~nm}$ argon laser.

Imaging irreversibly bound DIDS in HeLa cells. Cells were grown on coverslips in the absence of serum for $22 \mathrm{~h}$ followed by incubation with DIDS (at either 50 or $500 \mu \mathrm{M}$ ) or without for $2 \mathrm{~h}$ at $37^{\circ} \mathrm{C}$. Next cells were washed to eliminate unbound DIDS and fixed with Bouin's solution $1: 1$ for $5 \mathrm{~min}$ followed by four washes with ethanol at 70\%. DIDS fluorescence imaging was carried out with a confocal microscope (Zeiss LSM 700) using a $\times 63$ objective and a 405-nm argon laser.

\section{Statistical analyses}

All data are presented as mean \pm S.E.M., $n=$ number of independent experiments. Statistical significance was evaluated by using ANOVA and Tukey multiple comparison tests. The difference between two means was considered to be significant if $P<0.05$.

\section{ABBREVIATIONS}

2-APB, 2-amino ethoxydiphenyl borate; AVD, apoptotic volume decrease; DMSO, dimethyl sulfoxide; DTT, DL-dithiothreitol; EDTA ethylenediaminetetraacetic acid; EGTA, ethylene glycol tetraacetic acid; PARP, poly ADP ribose polymerase; PMCA, plasma membrane calcium ATPase; PMP, plasma membrane potential; PVDF, polyvinyldene fluoride; STS, staurosporine; TNF, tumor necrosis factor; VDAC, voltagedependent anion channel.

\section{ACKNOWLEDGEMENTS}

We thank Nicolas Villegas for insightful discussions on the effect of water on the activity of DIDS, Veronica Diez for technical assistance with caspase-3 western blots and Robert M Drummond for critical reading of the manuscript. EB-R was partially supported by CONACYT fellowship \#162555 and a postdoctoral fellowship from DGAPA-UNAM. MCL-M was supported by CONACYT fellowship \#243452. AG-H was partially supported by CONACYT grant \#128735.

\section{COMPETING INTERESTS}

The authors declare no conflict of interest.

\section{REFERENCES}

1 Okada Y, Maeno E. Apoptosis, cell volume regulation and volume-regulatory chloride channels. Comp Biochem Physiol A Mol Integr Physiol, United States 2001 377-383.

2 Remillard CV, Yuan JX. Activation of K+ channels: an essential pathway in programmed cell death. Am J Physiol Lung Cell Mol Physiol 2004; 286: L49-L67.

3 Lang F, Huber SM, Szabo I, Gulbins E. Plasma membrane ion channels in suicidal cell death. Arch Biochem Biophys 2007; 462: 189-194.

4 Bortner CD, Cidlowski JA. Cell shrinkage and monovalent cation fluxes: role in apoptosis. Arch Biochem Biophys 2007; 462: 176-188.

5 Maeno E, Ishizaki Y, Kanaseki T, Hazama A, Okada Y. Normotonic cell shrinkage because of disordered volume regulation is an early prerequisite to apoptosis. Proc Natl Acad Sci USA 2000; 97: 9487-9492.

6 Okada Y, Shimizu T, Maeno E, Tanabe S, Wang X, Takahashi N. Volume-sensitive chloride channels involved in apoptotic volume decrease and cell death. J Membr Biol 2006; 209: 21-29.

7 Himi T, Ishizaki Y, Murota SI. 4,4'-diisothiocyano-2,2'-stilbenedisulfonate protects cultured cerebellar granule neurons from death. Life Sci 2002; 70: 1235-1249.

8 Krumschnabel G, Maehr T, Nawaz M, Schwarzbaum PJ, Manzl C. Staurosporineinduced cell death in salmonid cells: the role of apoptotic volume decrease, ion fluxes and MAP kinase signaling. Apoptosis 2007; 12: 1755-1768.

9 Tanabe S, Wang X, Takahashi N, Uramoto H, Okada Y. HCO(3)(-)-independent rescue from apoptosis by stilbene derivatives in rat cardiomyocytes. FEBS Lett 2005; 579: 517-522.

10 Takahashi N, Wang $\mathrm{X}$, Tanabe S, Uramoto $\mathrm{H}$, Jishage $\mathrm{K}$, Uchida $\mathrm{S}$ et al. $\mathrm{ClC}$-3-independent sensitivity of apoptosis to $\mathrm{Cl}$ - channel blockers in mouse cardiomyocytes. Cell Physiol Biochem 2005; 15: 263-270.

11 Dong Z, Wang J, Zhong Q. Postmitochondrial regulation of apoptosis by bicarbonate. Exp Cell Res 2003; 288: 301-312.

12 Sade H, Khandre NS, Mathew MK, Sarin A. The mitochondrial phase of the glucocorticoid-induced apoptotic response in thymocytes comprises sequential activation of adenine nucleotide transporter (ANT)-independent and ANTdependent events. Eur J Immunol 2004; 34: 119-125.

$13 \mathrm{Li}$ Q, Sato EF, Zhu X, Inoue M. A simultaneous release of SOD1 with cytochrome C regulates mitochondria-dependent apoptosis. Mol Cell Biochem 2009; 322: 151-159.

14 Godbole A, Varghese J, Sarin A, Mathew MK. VDAC is a conserved element of death pathways in plant and animal systems. Biochim Biophys Acta 2003; 1642 87-96.

15 Romero MF, Fulton CM, Boron WF. The SLC4 family of HCO 3 - transporters. Pflugers Arch 2004; 447: 495-509.

16 Tajeddine N, Galluzzi L, Kepp O, Hangen E, Morselli E, Senovilla L et al. Hierarchical involvement of Bak, VDAC1 and Bax in cisplatin-induced cell death. Oncogene 2008; 27: 4221-4232 
17 Shoshan-Barmatz V, Keinan N, Abu-Hamad S, Tyomkin D, Aram L. Apoptosis is regulated by the VDAC1 $\mathrm{N}$-terminal region and by VDAC oligomerization: release of cytochrome C, AIF and Smac/Diablo. Biochim Biophys Acta 2010; 1797: 1281-1291.

18 Keinan N, Tyomkin D, Shoshan-Barmatz V. Oligomerization of the mitochondrial protein voltage-dependent anion channel is coupled to the induction of apoptosis. Mol Cell Biol 2010; 30: 5698-5709.

19 Shoshan-Barmatz V, Hadad N, Feng W, Shafir I, Orr I, Varsanyi M et al. VDAC/porin is present in sarcoplasmic reticulum from skeletal muscle. FEBS Lett 1996; 386: 205-210.

20 Okubo K, Kang D, Hamasaki N, Jennings ML. Red blood cell band 3. Lysine 539 and lysine 851 react with the same H2DIDS (4,4'-diisothiocyanodihydrostilbene-2, 2'-disulfonic acid) molecule. J Biol Chem 1994; 269: 1918-1926.

21 Santos FT, Scofano HM, Barrabin H, Meyer-Fernandes JR, Mignaco JA. A novel role of 4,4'-diisothiocyanatostilbene-2,2'-disulfonic acid as an activator of the phosphatase activity catalyzed by plasma membrane Ca2+-ATPase. Biochemistry 1999; 38: 10552-10558.

22 Kowaltowski AJ, Vercesi AE, Castilho RF. Mitochondrial membrane protein thiol reactivity with $\mathrm{N}$-ethylmaleimide or mersalyl is modified by $\mathrm{Ca2+:}$ correlation with mitochondrial permeability transition. Biochim Biophys Acta 1997; 1318: 395-402.

23 Bernardes CF, Meyer-Fernandes JR, Basseres DS, Castilho RF, Vercesi AE. $\mathrm{Ca}(2+)$-dependent permeabilization of the inner mitochondrial membrane by 4,4'-diisothiocyanatostilbene-2,2'-disulfonic acid (DIDS). Biochim Biophys Acta 1994; 1188: 93-100

24 Sauvé R, Simoneau C, Parent L, Monette R, Roy G. Oscillatory activation of calcium-dependent potassium channels in HeLa cells induced by histamine H1 receptor stimulation: a single-channel study. J Membr Biol 1987; 96: 199-208.

25 Shimizu S, Matsuoka Y, Shinohara Y, Yoneda Y, Tsujimoto Y. Essential role of voltage-dependent anion channel in various forms of apoptosis in mammalian cells. J Cell Biol 2001; 152: 237-250.

26 Benítez-Rangel E, García L, Namorado MC, Reyes JL, Guerrero-Hernández A. Ion channel inhibitors block caspase activation by mechanisms other than restoring intracellular potassium concentration. Cell Death Dis 2011; 2: e113.

27 Maruyama T, Kanaji T, Nakade S, Kanno T, Mikoshiba K. 2APB, 2-aminoethoxydiphenyl borate, a membrane-penetrable modulator of $\operatorname{Ins}(1,4,5)$ P3-induced Ca2+ release. J Biochem 1997; 122: 498-505.

28 Gregory RB, Rychkov G, Barritt GJ. Evidence that 2-aminoethyl diphenylborate is a novel inhibitor of store-operated $\mathrm{Ca} 2+$ channels in liver cells, and acts through a mechanism which does not involve inositol trisphosphate receptors. Biochem $J$ 2001; 354: 285-290.
29 Togashi $\mathrm{K}$, Inada H, Tominaga M. Inhibition of the transient receptor potential cation channel TRPM2 by 2-aminoethoxydiphenyl borate (2-APB). Br J Pharmacol 2008; 153: 1324-1330

30 Greenwood IA, Leblanc N. Overlapping pharmacology of Ca2+-activated Cl- and K + channels. Trends Pharmacol Sci 2007; 28: 1-5.

31 Soldani C, Scovassi Al. Poly(ADP-ribose) polymerase-1 cleavage during apoptosis: an update. Apoptosis 2002; 7: 321-328.

32 Wöll E, Gschwentner M, Fürst J, Hofer S, Buemberger G, Jungwirth A et al. Fluorescence-optical measurements of chloride movements in cells using the membrane-permeable dye diH-MEQ. Pflugers Arch 1996; 432: 486-493.

33 Ernest NJ, Habela CW, Sontheimer H. Cytoplasmic condensation is both necessary and sufficient to induce apoptotic cell death. J Cell Sci 2008; 121: 290-297.

34 Matulef K, Howery AE, Tan L, Kobertz WR, Du Bois J, Maduke M. Discovery of potent CLC chloride channel inhibitors. ACS Chem Biol 2008; 3: 419-428.

35 Madesh M, Hajnóczky G. VDAC-dependent permeabilization of the outer mitochondrial membrane by superoxide induces rapid and massive cytochrome c release. J Cell Biol 2001; 155: 1003-1015.

36 Inoue H, Ohtaki H, Nakamachi T, Shioda S, Okada Y. Anion channel blockers attenuate delayed neuronal cell death induced by transient forebrain ischemia. J Neurosci Res 2007; 85: 1427-1435.

37 Fang B, Boross Pl, Tozser J, Weber IT. Structural and kinetic analysis of caspase-3 reveals role for s5 binding site in substrate recognition. $J$ Mol Biol 2006; 360: 654-666.

38 Pamenter ME, Perkins GA, Gu XQ, Ellisman MH, Haddad GG. DIDS (4,4-diisothiocyanatostilbenedisulphonic acid) induces apoptotic cell death in a hippocampal neuronal cell line and is not neuroprotective against ischemic stress. PLoS One 2013; 8: e60804.

39 Bootman MD, Cheek TR, Moreton RB, Bennett DL, Berridge MJ. Smoothly graded $\mathrm{Ca} 2+$ release from inositol 1,4,5-trisphosphate-sensitive Ca2+ stores. J Biol Chem 1994; 269: 24783-24791

40 Garcia-Calvo M, Peterson EP, Rasper DM, Vaillancourt JP, Zamboni R, Nicholson DW et al. Purification and catalytic properties of human caspase family members. Cell Death Differ 1999; 6: 362-369.

\begin{abstract}
his work is licensed under a Creative Commons Attribution 4.0 International License. The images or other third party material in this article are included in the article's Creative Commons license, unless indicated otherwise in the credit line; if the material is not included under the Creative Commons license, users will need to obtain permission from the license holder to reproduce the material. To view a copy of this license, visit http://creativecommons.org/licenses/ by/4.0/
\end{abstract}

Supplemental Information accompanies the paper on the Cell Death Discovery website (http://www.nature.com/cddiscovery) 